\title{
Produção de farinhas a partir de carcaças de tilápia, pacu e carpa para inclusão em produtos alimentícios
}

\author{
Fish meal production from tilapia, pacu and carp carcasses for inclusion in food products \\ Producción de harina a partir de canales de tilapia, pacu y carpa para su inclusión en productos \\ alimenticios
}

Maria Luiza Rodrigues de Souza ORCID: https://orcid.org/0000-0001-5643-0841 Universidade Estadual de Maringá, Brasil E-mail: mlrsouza@uem.br

Leandro Cesar de Godoy ORCID: https://orcid.org/0000-0002-6236-9749 Universidade Federal do Rio Grande do Sul, Brasil

E-mail: leandro.godoy@ufrgs.br

Jesuí Vergílio Visentainer

ORCID: https://orcid.org/0000-0003-3412-897X

Universidade Estadual de Maringá, Brasil

E-mail: jesuivvisntainer@uem.br

Nilson Evelazio de Souza

ORCID: https://orcid.org/0000-0002-2813-3513

Universidade Estadual de Maringá, Brasil

E-mail: nilsonesouza@uem.br (in memorian)

Nilson do Prado Franco

ORCID: https://orcid.org/0000-0002-9309-2973 Zootecnista, Brasil E-mail: Leandro.godoy@ufrgs.br

Gislaine Gonçalves Oliveira

ORCID: https://orcid.org/0000-0002-7819-3493 Universidade Estadual de Maringá, Brasil E-mail: gislaine_oliveira14@hotmail.com

Andresa Carla Feihrmann

ORCID: https://orcid.org/0000-0003-2389-0467 Universidade Estadual de Maringá, Brasil E-mail: andresafeihrmann@gmail.com

Elenice Souza dos Reis Goes

ORCID: https://orcid.org/0000-0003-2437-4800 Universidade Federal da Grande Dourados, Brasil

E-mail: elenicegoes@ufgd.edu.br

\begin{abstract}
Resumo
O objetivo deste estudo foi desenvolver e caracterizar farinhas a partir de carcaças de tilápia, pacu e carpa para inclusão em produtos alimentícios, visando o enriquecimento nutricional. Carcaças das três espécies foram defumadas a quente e posteriormente submetidas a moagem, resultando nas farinhas. Foram realizadas análises dos rendimentos do processo, composição centesimal, cálcio, ferro, fósforo, ácidos graxos e análises microbiológicas. Os rendimentos das carcaças in natura, defumadas e do processo de defumação foram superiores para a tilápia. As carcaças in natura de tilápia e carpa apresentaram valores superiores de umidade e proteína bruta em relação à carcaça de pacu. A farinha elaborada a partir das carcaças de carpa apresentou maior teor de proteína bruta (36,15\%). A farinha de pacu apresentou teor de lipídios significativamente maior (26,33\%) em relação às de tilápia e carpa. Foram identificados 23 ácidos graxos nas farinhas elaboradas. Os que tiveram maior representatividade foram o 18:1n-9 (oléico), 16:0 (palmítico), 18:2n-6 (linoléico), 18:0 (esteárico) e 16:1n-7 (palmitoleico). As farinhas apresentaram-se como produtos de elevado teor de proteína bruta, minerais (cálcio, ferro e fósforo) e lipídios totais, além de possuírem em suas composições, ácidos graxos essenciais à dieta humana. A análise microbiológica das farinhas demonstrou resultados dentro dos limites estabelecidos pela legislação brasileira. Portanto, as farinhas de peixe obtidas no presente estudo podem ser utilizadas no enriquecimento de diversos produtos para o consumo humano.

Palavras-chave: Ácidos graxos; Carcaça de carpa; Espinhaço de tilápia; Resíduos de pacu.
\end{abstract}




\begin{abstract}
The aim of this study was to develop and characterize flours from tilapia, pacu and carp carcasses for inclusion in food products, aiming at nutritional enrichment. Carcasses of the three species were hot smoked and later subjected to milling, resulting in flour. Analyzes of process yields, proximate composition, calcium, iron, phosphorus, fatty acids and microbiological analysis were carried out. The yields of in natura, smoked and smoking carcasses were higher for tilapia. Tilapia and carp in natura carcasses had higher moisture and crude protein values than pacu carcasses. The flour made from carp carcasses had the highest crude protein content $(36.15 \%)$. Pacu flour had significantly higher lipid content $(26.33 \%)$ compared to tilapia and carp. 23 fatty acids were identified in the prepared flours. Those that had the greatest representation were 18:1n-9 (oleic), 16:0 (palmitic), 18:2n-6 (linoleic), 18:0 (stearic) and 16:1n-7 (palmitoleic). The flours were presented as products with a high content of crude protein, minerals (calcium, iron and phosphorus) and total lipids, in addition to having in their compositions essential fatty acids for the human diet. The microbiological analysis of the flours showed results within the limits established by Brazilian legislation. Therefore, the fishmeal obtained in this study can be used to enrich various products for human consumption.
\end{abstract}

Keywords: Fatty acids; Carp carcass; Tilapia spine; Pacu waste.

\title{
Resumen
}

El objetivo de este estudio fue desarrollar y caracterizar harinas de carcasas de tilapia, pacu y carpa para su inclusión en productos alimenticios, con el objetivo de enriquecimiento nutricional. Las canales de las tres especies fueron ahumadas en caliente y luego sometidas a molienda, dando como resultado harina. Se realizaron análisis de rendimientos del proceso, composición próxima, calcio, hierro, fósforo, ácidos grasos y análisis microbiológicos. Los rendimientos de canales in natura, ahumados y ahumados fueron mayores para la tilapia. Las canales de tilapia y carpa in natura presentaron valores de humedad y proteína cruda más altos que las canales de pacu. La harina elaborada a partir de canales de carpa presentó el mayor contenido de proteína cruda $(36,15 \%)$. La harina de pacu tuvo un contenido de lípidos significativamente mayor (26,33\%) en comparación con la tilapia y la carpa. Se identificaron 23 ácidos grasos en las harinas preparadas. Los que tuvieron mayor representación fueron 18: 1n-9 (oleico), 16: 0 (palmítico), 18: 2n-6 (linoleico), 18: 0 (esteárico) y 16: 1n-7 (palmitoleico). Las harinas se presentaron como productos con un alto contenido de proteína cruda, minerales (calcio, hierro y fósforo) y lípidos totales, además de tener en sus composiciones ácidos grasos esenciales para la dieta humana. El análisis microbiológico de las harinas arrojó resultados dentro de los límites establecidos por la legislación brasileña. Por tanto, la harina de pescado obtenida en este estudio puede utilizarse para enriquecer diversos productos para el consumo humano.

Palavras clave: Ácidos grasos; Canal de carpa; Espina dorsal de tilapia; Residuos de pacu.

\section{Introdução}

O peixe tem sido reconhecido como componente integrante de uma dieta balanceada e saudável, sendo fonte de energia, proteínas de alta qualidade, vitaminas ( $\mathrm{D}, \mathrm{A}, \mathrm{E}$ e $\mathrm{B}_{12}$ ), metais essenciais ( $\mathrm{Se}, \mathrm{Mn}$ e $\mathrm{Cu}$ ) e ácidos graxos poli-insaturados de cadeia longa n-3, principalmente ácido eicosapentaenoico (EPA, 20:5n-3) e docosaexaenoico (DHA, 22:6n-3), cujos efeitos na promoção da saúde e prevenção de doenças são cada vez mais conhecidos (Gil \& Gil, 2015).

A produção de peixes no Brasil atingiu 802.930 toneladas em 2020, e deste total, $60 \%$ é representado pela tilápia do Nilo (Peixe BR, 2021). Os peixes nativos também representam um segmento muito importante da piscicultura, com produção de 278.671 t em 2020, liderados principalmente pelo tambaqui (Peixe BR, 2021). Outras espécies também são de interesse da piscicultura, como pacu, patinga, carpa, pintado, cachara, entre outros. Da produção total de 2019, 2,2\% foi representada pelo pacu e patinga, e $3,4 \%$ pelas carpas (IBGE, 2020).

Percebe-se um aumento crescente na produção de peixes, e os dados demonstram um crescimento de 38,7\% nos últimos seis anos (Peixe BR, 2021). O aumento da produção de peixes contribui para a maior geração de resíduos, que acabam como descartes.

O duplo problema das indústrias de processamento de pescado, que compreende as questões ambientais e as aplicações menos rentáveis de subprodutos e resíduos, têm realçado a necessidade de valorizar os resíduos de processamento de pescado e ao mesmo tempo, contribuir para uma indústria mais sustentável (Idea et al., 2020). Os resíduos do processamento de peixes, são compostos por cabeças, escamas, peles, vísceras e carcaças (esqueleto com carne aderida). Dependendo da espécie de peixe processada e do produto final obtido pelo frigorífico, estes resíduos podem representar cerca de $60 \%$ do peso total do pescado 
(Idea et al., 2020).

Sabe-se que os compostos saudáveis presentes nos peixes também fazem parte de seus subprodutos (Pateiro et al., 2020), que atualmente, são utilizados principalmente na alimentação animal, através da elaboração de óleo e farinha de peixe, e também como fertilizantes vegetais (Marti-Quijal et al., 2020). No entanto, considerando o valor nutricional destes subprodutos, a utilização deles para elaboração de produtos com maior valor agregado, destinados ao consumo humano, pode ser economicamente mais atrativa para a indústria pesqueira.

Nesse sentido, as farinhas de peixe vêm sendo estudadas e apresentadas como viáveis para serem utilizadas no enriquecimento e preparo de diversos produtos para consumo humano (Godoy et al., 2013; Souza et al., 2017). A criação de alternativas tecnológicas, que permitam o gerenciamento dos resíduos de pescado, pode trazer como resultado a geração de empregos e o desenvolvimento sustentável, além de agregar valor a partes comestíveis desvalorizadas economicamente. Sendo assim, é vital o estudo de novas tecnologias para transformar esses subprodutos ou resíduos de filetagem de peixes em produtos de maior valor agregado.

Portanto, este trabalho objetivou avaliar a utilização de carcaças (espinhaço com carne remanescente da filetagem) de tilápia do Nilo, carpa e pacu defumadas com ervas aromáticas na elaboração de farinhas aromatizadas, analisar o rendimento no processamento, e caracterizar as farinhas em relação à composição e qualidade microbiológica.

\section{Metodologia}

\section{Procedimento de elaboração das farinhas de tilápia, pacu e carpa}

Foram utilizadas 100 carcaças (coluna vertebral com as costelas e sem cabeça e nadadeiras, com a presença da carne remanescente da filetagem) de tilápia do Nilo (Oreochromis niloticus), carpa (Cyprinus carpio) e pacu (Piaractus mesopotamicus) provenientes de pesque-pagues da região Noroeste do Paraná. Foram realizadas pesagens para determinação das médias de peso corporal no abate, e após o processo de filetagem e obtenção das carcaças, foram determinados os pesos das carcaças in natura e pesos das carcaças defumadas das três espécies.

Após serem lavadas e escorridas, as carcaças foram pesadas individualmente, identificadas com placas metálicas e imersas por 15 minutos em salmoura com concentração de $20 \%(\mathrm{~m} / \mathrm{v})$ de $\mathrm{NaCl}$ contendo alecrim desidratado na proporção de 0,04\% (m/v). Em seguida, foram dependuradas pela região caudal com o auxílio de ganhos por 1 hora, para drenagem e redução da água superficial. Após esta etapa, as carcaças foram colocadas dentro da câmara de defumação, para secagem parcial a uma temperatura de $50^{\circ} \mathrm{C}$, durante 60 minutos. Decorrido esse período, iniciou-se a adição de fumaça. Para a defumação, utilizou-se um defumador artesanal de aço inox, com geração de fumaça externa à câmara de defumação. Para a produção da fumaça utilizou-se serragem obtida do eucalipto rosa (Eucalyptus globulus Labill) e para manter a temperatura do defumador foi utilizado gás de cozinha.

Para o processo de adição de fumaça a temperatura foi de $60^{\circ} \mathrm{C}$ e a cada hora houve um aumento de $10^{\circ} \mathrm{C}$, até atingir $80{ }^{\circ} \mathrm{C}$, totalizando 3 horas de exposição das carcaças à fumaça. As carcaças defumadas foram pesadas para o cálculo de rendimento e submetidas à moagem em moinho tipo faca (Willye - modelo TE-650, Tecnal Equipamentos Científicos, Brasil) para obtenção das farinhas (Figura 1). Amostras das farinhas obtidas foram embaladas a vácuo (SUPERVAC SVC-200, Supervac Indústria e Comércio Ltda, Brasil), identificadas e congeladas em freezer horizontal (H500, Electrolux, Brasil) (a -18 ${ }^{\circ} \mathrm{C}$ até o momento das análises. 
Figura 1. Processo de elaboração das farinhas: (A) Filetagem dos peixes; (B) Carcaças codificadas prontas para a salmouragem; (C) Secagem parcial; (D) Defumação; (E) Carcaças defumadas; (F) Moagem; (G) Obtenção das farinhas; (H) Embalagem a vácuo.
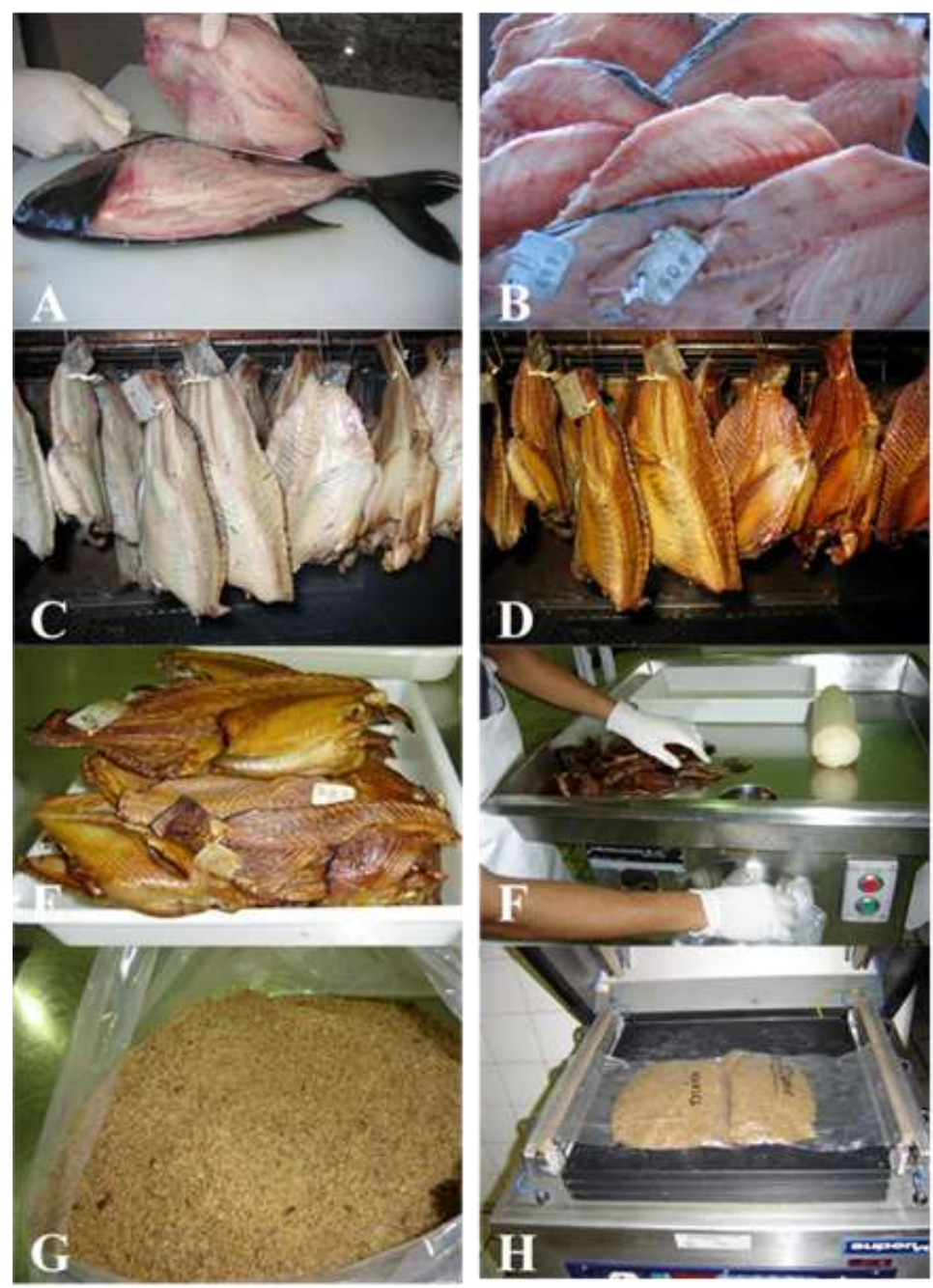

Fonte: Autores (2021).

\section{Análises químicas}

Foram realizadas análises de composição centesimal das carcaças in natura e das farinhas, obtidas após a defumação. c até se obter uma massa homogênea. Amostras das massas e das farinhas foram utilizadas para as determinações da composição centesimal. Os teores de umidade (método $n^{\circ}$ 931.04) e cinzas (método $n^{\circ}$ 923.03) foram determinados conforme AOAC (2010), e os teores de proteína bruta pelo método semi-micro Kjeldahl, descrito por Silva e Queiroz (2002). Na extração dos lipídios totais, foi empregado o método de Bligh \& Dyer (1959).

Para as análises de cálcio e ferro, a digestão das amostras foi realizada em meio ácido, utilizando $\mathrm{HCl}$, e as determinações realizadas por espectrometria de absorção atômica com chama (FAAS, do inglês Flame Atomic Absorption Spectrometry) (Zhou et al., 1998). As determinações de fósforo total foram realizadas utilizando fosfomolibdato de amônio por espectrofotometria UV-VIS (espectrofotômetro DR-5000, Hatch, Alemanha) (Eijsink et al., 1997).

Para a determinação dos perfis de ácidos graxos das carcaças in natura e das farinhas, as amostras de lipídios totais foram transesterificadas conforme Método 5509 (ISO, 1978). Os ésteres metílicos foram separados em cromatógrafo gasoso (Shimadzu, 14-A, Japão), equipado com detector de ionização de chama e coluna capilar de sílica fundida (Carbowax 20M, 100 $\mathrm{m} \times 0,25 \mathrm{~mm}, 0,20 \mu \mathrm{m})$. As áreas dos picos (percentagens de áreas relativas) foram integradas por um integrador-processador 
CG-300 (instrumentos científicos). As identificações dos ácidos graxos foram efetuadas pelos seguintes critérios: comparação dos tempos de retenção de ésteres metílicos de padrões da Sigma-Aldrich (EUA) com os das amostras, e comparação dos valores de comprimento equivalente de cadeia (ECL, do inglês Equivalent Chain Lenght) dos ésteres metílicos das amostras com valores da literatura (Silva, 2000; Strànsky et al., 1997; Visentainer, 2003).

\section{Análises microbiológicas}

Amostras das carcaças in natura e das farinhas elaboradas foram destinadas às análises microbiológicas. Foram determinados coliformes a $35^{\circ} \mathrm{C} \mathrm{e} 45^{\circ} \mathrm{C}$, contagem de Estafilococos coagulase positiva e presença de Salmonella spp, de acordo com metodologia de APHA (2001).

Os coliformes foram determinados pela técnica do Número Mais Provável (NMP) usando uma série de três tubos de Caldo Lauril Sulfato Triptose (Difco, Becton Dickinson, Sparks, EUA) que foram incubados a $35^{\circ} \mathrm{C}$ por $48 \mathrm{~h}$. Os tubos que apresentavam produção de gases foram transferidos para Green Bile Lactose Broth (Difco, Becton Dickinson, Sparks, MD, EUA) e incubados a $35{ }^{\circ} \mathrm{C}$ por $48 \mathrm{~h}$, e para caldo EC e incubados a $45^{\circ} \mathrm{C}$ por $48 \mathrm{~h}$. Os resultados foram dados em NMP / g.

Para contagens de Estafilococos coagulase positiva, foi usada a técnica de espalhamento em ágar Baird Parker (Difco, Becton Dickinson, Sparks, EUA). As placas foram incubadas a $35{ }^{\circ} \mathrm{C}$ durante $48 \mathrm{~h}$ e os resultados foram apresentados em UFC/grama.

A presença de Salmonella spp. foi avaliada pela adição de $25 \mathrm{~g}$ das amostras a $225 \mathrm{~mL}$ de caldo de lactose (Difco, Becton Dickinson, Sparks, EUA) e incubado a $35^{\circ} \mathrm{C}$ por $24 \mathrm{~h}$. Posteriormente, uma alíquota foi inoculada em Caldo Selenita Cistina (Difco, Becton Dickinson, Sparks, EUA) e em meio Rappaport-Vassiliadis (Difco, Becton Dickinson, Sparks, EUA) e incubada a $35^{\circ} \mathrm{C}$ por $24 \mathrm{~h}$, e a $42{ }^{\circ} \mathrm{C}$ por $48 \mathrm{~h}$, respectivamente. Após o período de incubação, as amostras enriquecidas foram semeadas em Agar Hektoen e incubadas a $35^{\circ} \mathrm{C}$ por 24 h. Colônias típicas foram submetidas a testes bioquímicos e sorológicos.

\section{Delineamento experimental}

Foi aplicado um delineamento inteiramente casualizado. As carcaças foram distribuídas aleatoriamente na câmara de defumação, sendo utilizadas como unidade experimental para todos os parâmetros utilizados. Para os cálculos de rendimento (peso da carcaça defumada $\times 100$ /peso no abate), cada carcaça foi considerada uma unidade experimental. Para determinação da composição química das carcaças in natura e das farinhas elaboradas, as análises foram realizadas em triplicata e as médias comparadas pelo teste de Tukey $(\mathrm{P}<0,05)$. Os dados foram processados utilizando o programa computacional Statistical Analysis System (SAS, SAS Inst. Inc. Cary, NC, USA). Para o perfil de ácidos graxos e as análises microbiológicas, os resultados foram somente descritivos para cada tratamento.

\section{Resultados e Discussão}

\section{Rendimentos no processamento}

Os pesos médios para tilápia, carpa e pacu, foram de $670 \mathrm{~g}, 660 \mathrm{~g}$ e $1230 \mathrm{~g}$, respectivamente. Os pesos das carcaças antes e após a defumação estão dispostos na Figura 2. 
Figura 2. Médias de peso corporal no abate, peso das carcaças in natura e peso das carcaças defumadas das três espécies que foram processadas para elaboração das farinhas.

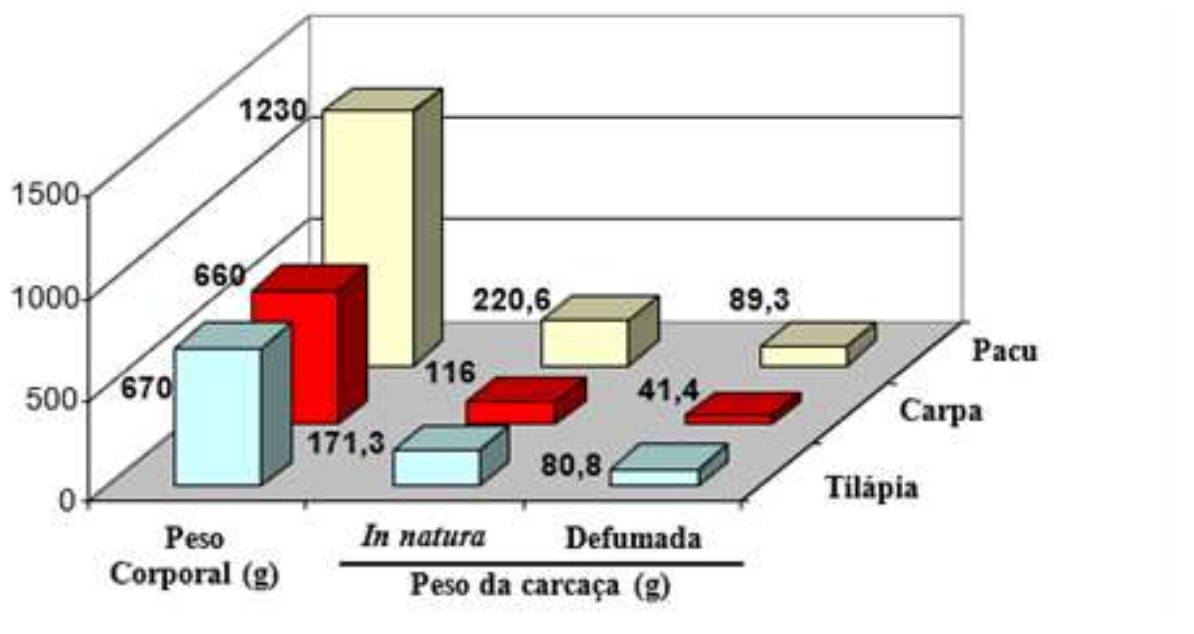

Fonte: Autores.

O rendimento das carcaças in natura e defumadas em relação ao peso total (RCI/PT e RCD/PT, respectivamente) das espécies analisadas foi estatisticamente superior $(\mathrm{P}<0,05)$ para a tilápia, não diferindo entre as carcaças de carpa e pacu $($ Tabela 1). Analisando o rendimento no processo de defumação, tendo como referência a carcaça in natura (RCD/PC), os resultados foram estatisticamente superiores para a tilápia $(47,17 \%)$ e inferiores para a carpa $(35,69 \%)$. A espécie que apresentou maior perda durante o processo de defumação (PD/PC) foi a carpa, enquanto a tilápia apresentou a menor perda (Tabela 1).

Tabela 1. Valores médios do rendimento das carcaças in natura em relação ao peso total (RCI/PT), rendimento das carcaças defumadas em relação ao peso total (RCD/PT), rendimento no processo de defumação em relação ao peso da carcaça (RCD/PC) e perdas no processo de defumação em relação ao peso da carcaça in natura (PD/PC).

\begin{tabular}{ccccc}
\hline Espécie & RCI/PT $(\%)$ & RCD/PT $(\%)$ & RCD/PC $(\%)$ & PD/PC $(\%)$ \\
\hline Tilápia & $25,57 \pm 1,56^{\mathrm{a}}$ & $12,06 \pm 1,98^{\mathrm{a}}$ & $47,17 \pm 1,67^{\mathrm{a}}$ & $52,83 \pm 3,51^{\mathrm{c}}$ \\
Carpa & $17,58 \pm 2,32^{\mathrm{b}}$ & $6,27 \pm 2,01^{\mathrm{b}}$ & $35,69 \pm 2,45^{\mathrm{c}}$ & $64,31 \pm 1,73^{\mathrm{a}}$ \\
Pacu & $17,93 \pm 2,21^{\mathrm{b}}$ & $7,26 \pm 2,10^{\mathrm{b}}$ & $40,48 \pm 1,58^{\mathrm{b}}$ & $59,52 \pm 1,16^{\mathrm{b}}$ \\
\hline Teste F & $69,59^{*}$ & $82,29^{*}$ & $15,19^{*}$ & $15,28^{*}$ \\
C.V $(\%)$ & 14,79 & 22,16 & 19,27 & 13,48 \\
\hline
\end{tabular}

Médias \pm desvio padrão seguidas de letras iguais na mesma coluna não diferem significativamente pelo Teste de Tukey $(\mathrm{P}>0,05)$. Diferença significativa entre pelo menos duas amostras $(\mathrm{P}<0,05)$. Fonte: Autores $(2021)$.

Segundo Ikape \& Solomon (2018), o peso e o formato do peixe têm efeitos sobre o rendimento no processamento. No entanto, outros fatores podem influenciar no rendimento, seja no momento da filetagem e/ou na defumação. O rendimento da filetagem depende de vários fatores como tamanho, anatomia estrutural dos peixes, sexo, espécie e condições de alimentação (Rodríguez et al., 2010). Além disso, fatores tecnológicos afetam o rendimento, como o método de filetagem, corte de cabeça e retirada da pele, forma de retirada da pele, sequência de remoção da pele (pele e filé ou vice-versa), grau de mecanização da unidade de beneficiamento e a capacitação do operador de filetagem (Pinheiro et al., 2006; Souza, 2002; Souza, 2003).

\section{Composição centesimal}

As carcaças in natura de tilápia e carpa apresentaram valores estatisticamente superiores de umidade e proteína bruta em relação à carcaça de pacu (Tabela 2). As carcaças de pacu apresentaram teor médio de lipídios totais superior às de carpas, 
não diferindo estatisticamente das carcaças de tilápia. Não houve diferença estatística no teor de cinzas entre as espécies.

Tabela 2. Valores médios da composição centesimal das carcaças in natura das diferentes espécies de peixes.

\begin{tabular}{lcccc}
\hline Carcaça in natura & Umidade $(\%)$ & Proteína Bruta $(\%)$ & Lipídios Totais $(\%)$ & Cinzas $(\%)$ \\
\hline Tilápia & $68,40 \pm 0,74^{\mathrm{a}}$ & $14,93 \pm 0,62^{\mathrm{a}}$ & $7,50 \pm 1,05^{\mathrm{ab}}$ & $6,31 \pm 0,56^{\mathrm{a}}$ \\
Carpa & $71,68 \pm 4,02^{\mathrm{a}}$ & $14,99 \pm 0,68^{\mathrm{a}}$ & $4,86 \pm 2,12^{\mathrm{b}}$ & $5,72 \pm 0,03^{\mathrm{a}}$ \\
Pacu & $62,89 \pm 3,18^{\mathrm{b}}$ & $13,02 \pm 1,29^{\mathrm{b}}$ & $13,28 \pm 4,73^{\mathrm{a}}$ & $5,22 \pm 0,53^{\mathrm{a}}$ \\
\hline Teste F & $28,27^{*}$ & $13,16^{*}$ & $15,07^{*}$ & $1,50 \mathrm{~ns}$ \\
C.V $(\%)$ & 1,75 & 3,05 & 18,37 & 10,96 \\
\hline
\end{tabular}

Médias \pm desvio padrão seguidas de letras iguais na mesma coluna não diferem significativamente pelo Teste de Tukey $(\mathrm{P}>0,05)$. ns diferença não significativa $(\mathrm{P}>0,05)$; * Diferença significativa entre pelo menos duas amostras $(\mathrm{P}<0,05)$. Fonte: Autores $(2021)$.

O processo de defumação alterou a composição das carcaças, resultando na redução da umidade de $62,89 \%$ para $37,79 \%$ para o pacu e de $71,68 \%$ para $24,76 \%$ para a carpa. A redução foi menor para o pacu (62,20\%), principalmente por ser uma espécie de peixe com maior teor de gordura (13,28\%). Já a carcaça da carpa apresentou menor teor de gordura (4,86\%), consequentemente a perda de umidade foi maior $(75,23 \%)$. A tilápia apresentou valor intermediário de lipídios $(7,50 \%)$, e também teve alta perda de umidade.

As farinhas elaboradas apresentaram maiores teores de proteína bruta, lipídios totais e cinzas, quando comparadas às carcaças in natura (Tabela 2 e Tabela 3). Segundo Sigurgisladottir et al. (2000) a proteína bruta e os lipídios são mais elevados no pescado defumado do que no pescado in natura, principalmente devido à perda de peso, que é tanto devido à desidratação, quanto à lixiviação de lipídios do músculo.

Houve diferença estatística entre pelo menos duas amostras de farinha em relação aos teores de proteína bruta, lipídios totais e cinzas (Tabela 3). Todavia, não houve diferença estatística no teor de umidade das farinhas $(\mathrm{P}>0,05)$, variando de $17,75 \%$ a 23,77\%. Isto se deve ao controle adotado na desidratação (controle da temperatura e do tempo de exposição das carcaças), além da distribuição aleatória das carcaças dentro da câmara de defumação. A farinha de carpa apresentou o maior teor de proteína bruta em relação às demais farinhas, enquanto a farinha de pacu apresentou o maior teor lipídico e a farinha de tilápia apresentou o maior teor de cinzas.

Tabela 3. Valores médios da composição centesimal das farinhas elaboradas com diferentes espécies de peixes.

\begin{tabular}{lllll}
\hline Farinha & Umidade $(\%)$ & Proteína Bruta $(\%)$ & Lipídios Totais $(\%)$ & Cinzas $(\%)$ \\
\hline Tilápia & $18,96 \pm 0,12^{\mathrm{a}}$ & $33,21 \pm 0,15^{\mathrm{b}}$ & $18,22 \pm 0,72^{\mathrm{b}}$ & $27,40 \pm 0,66^{\mathrm{a}}$ \\
Carpa & $17,75 \pm 2,41^{\mathrm{a}}$ & $36,15 \pm 3,09^{\mathrm{a}}$ & $19,80 \pm 0,92^{\mathrm{b}}$ & $23,44 \pm 0,78^{\mathrm{b}}$ \\
Pacu & $23,77 \pm 3,61^{\mathrm{a}}$ & $29,81 \pm 2,25^{\mathrm{b}}$ & $26,33 \pm 0,56^{\mathrm{a}}$ & $18,91 \pm 0,55^{\mathrm{c}}$ \\
\hline Teste F & $3,20 \mathrm{~ns}$ & $6,96^{*}$ & $5,34^{*}$ & $42,45^{*}$ \\
C.V $(\%)$ & 28,76 & 10,05 & 20,80 & 6,70 \\
\hline
\end{tabular}

Médias \pm desvio padrão seguidas de letras iguais na mesma coluna não diferem significativamente pelo Teste de Tukey $(\mathrm{P}>0,05)$. ns diferença não significativa $(\mathrm{P}>0,05)$; * Diferença significativa entre pelo menos duas amostras $(\mathrm{P}<0,05)$. Fonte: Autores $(2021)$.

$\mathrm{O}$ aumento no teor de cinzas ocorreu devido à redução da umidade e à absorção de cloreto de sódio pelas carcaças durante o processo da salmouragem. O mesmo foi observado por Gonçalves \& Prentice-Hernández (1998) e Souza et al. (2020). A farinha elaborada a partir das carcaças de pacu, que corresponde ao peixe com maior teor lipídico, apresentou o menor teor de 
cinzas. Segundo Rora et al. (1998) quanto maior o teor de gordura, menor a penetração do sal, o que está de acordo com os resultados encontrados

A espécie e o tipo de resíduo utilizado interferem muito na composição química da farinha (Souza et al., 2017). Quanto à espécie, refere-se principalmente ao teor de lipídeos, que interfere principalmente na redução do teor de umidade da farinha. Porém, outros fatores como o tempo de exposição no processo de defumação, a disposição das carcaças dependuradas na câmara de defumação, o tamanho das carcaças e o distanciamento entre elas dentro da câmara de defumação também interferem. Em relação ao processo de desidratação da farinha, deve-se considerar a temperatura aplicada, o tempo de desidratação e a disposição das bandejas dentro do desidratador, bem como a espessura da massa na bandeja. Todos esses são fatores que contribuem na composição da farinha de peixe.

Souza et al. (2017) elaboraram farinhas com resíduos de processamento de diversas espécies de peixes (atum, sardinha, tilápia e salmão), pelo método do cozimento. As carcaças foram cozidas por 60 minutos e em seguida, prensadas e moídas, resultando em uma massa, a qual foi submetida à desidratação a $60^{\circ} \mathrm{C}$ por 24 horas em desidratador com circulação forçada de ar. Os autores analisaram a composição das farinhas e obtiveram resultados com grande variação no teor de proteínas (44,65\% a $83,28 \%)$, lipídeos $(3,998 \%$ a $18,81 \%)$ e cinzas $(5,31 \%$ a $37,66 \%)$. Essa variação nos teores destes nutrientes deve-se às particularidades de cada espécie, além do resíduo utilizado. A farinha de atum apresentou 83,28\% de proteína e baixo teor de cinzas $(5,31 \%)$, devido à utilização da parte do tronco do peixe, com menor quantidade óssea comparada às farinhas das demais espécies, nas quais foram utilizadas também as costelinhas do espinhaço. A farinha de salmão apresentou o menor teor de proteína $(44,63 \%)$ e o maior teor de lipídeos $(18,81 \%)$. A farinha de tilápia apresentou o maior teor de cinzas $(37,66 \%)$, tendo $51,13 \%$ de proteína e 5,82\% de lipídeos. O método de elaboração da farinha utilizado por Souza et al. (2017) foi diferente ao deste experimento, o que pode influenciar na composição química da farinha.

No presente estudo, o teor de umidade das farinhas foi elevado $(17,75 \%$ a $23,77 \%)$, devido ao fato de as carcaças não terem sido prensadas após o processo de defumação. O mesmo ocorreu para o teor de lipídeos, que variou de 18,22\% a 26,33\%. O teor de umidade recomendado para farinha de pescado pelo Regulamento de Inspeção Industrial e Sanitária de produtos de Origem Animal (RIISPOA) é de 10\% (Brasil, 1997). Neste experimento os teores foram superiores (Tabela 3), o que dificulta principalmente o armazenamento, devido à maior predisposição das farinhas à ação de microrganismos.

Souza et al. (2021) produziram farinha de tilápia defumada, usando metodologia similar à utilizada neste experimento. Os autores obtiveram uma farinha com 9,50\% de umidade, $48,91 \%$ de proteína, 10,63\% de lipídeos e 30,05\% de cinzas. O menor teor de umidade comparado ao deste experimento, deve-se à prensagem da matéria-prima após cozimento, realizada pelos autores. Justen et al. (2017) aplicaram a mesma metodologia utilizada neste experimento para a produção de farinha de tilápia, porém, os autores prensaram as carcaças após defumação. As farinhas obtidas apresentaram 5,04\% de umidade, 45,50\% de proteína, $14,60 \%$ de lipídeos e $26,31 \%$ de cinzas. A prensagem proporcionou um menor teor de umidade e lipídeos na farinha, comparando com os resultados deste experimento, onde não foi aplicada prensagem após a defumação.

Portanto, verifica-se que são vários os fatores que interferem na composição química de uma farinha elaborada a partir de resíduos de filetagem ou de processamento de pescado. Uma limitação deste estudo foi não ter sido aplicada a técnica de prensagem das carcaças, objetivando diminuir o teor de umidade, uma vez que a umidade elevada influencia diretamente na qualidade microbiológica, sensorial e na vida de prateleira de um produto.

\section{Perfil de ácidos graxos}

Foram identificados 23 ácidos graxos nos lipídios totais das farinhas elaboradas (Tabela 4). Os que tiveram maior representatividade foram o 18:1n-9 (oléico), com valores variando de 33,74\% a 42,17\%; 16:0 (palmítico), de 20,78\% a 27,51\%; 18:2n-6 (linoléico), de 7,89\% a 19,40\%;, 18:0 (esteárico), de 5,44\% a 9,82\% e 16:1n-7 (palmitoleico), de 3,88\% a 6,73\% Clement 
e Lovell (1994) encontraram valores de 42,2\% para ácido oléico, 12,7\% para o ácido palmítico, 12,1\% para ácido linoléico, 6,7\% para o ácido palmitoleico e 6,3\% para ácido esteárico para filé de tilápia. Zara (2005) analisando filés de tilápia do Nilo submetidos à defumação com extrato aquoso de alecrim identificou valores semelhantes aos deste estudo.

Tabela 4. Composição de ácidos graxos $(\%)$ das farinhas elaboradas com diferentes espécies de peixes.

\begin{tabular}{lccc}
\hline Ácidos Graxos & Tilápia & Carpa & Pacu \\
\hline $14: 0$ & $2,79 \pm 1,55$ & $1,50 \pm 1,25$ & $1,63 \pm 1,98$ \\
$16: 0$ & $24,48 \pm 0,37$ & $20,78 \pm 1,75$ & $27,51 \pm 2,63$ \\
$16: 1$ n-7 & $5,32 \pm 1,80$ & $3,88 \pm 2,09$ & $6,73 \pm 1,09$ \\
$16: 1$ n-9 & $0,77 \pm 1,32$ & $0,80 \pm 2,21$ & $0,38 \pm 1,16$ \\
$17: 0$ & $0,32 \pm 0,51$ & $0,42 \pm 1,11$ & $0,19 \pm 0,59$ \\
$17: 1$ n-9 & $0,26 \pm 0,89$ & $0,31 \pm 1,31$ & $0,12 \pm 0,73$ \\
$18: 0$ & $5,44 \pm 2,21$ & $5,99 \pm 0,80$ & $9,82 \pm 2,16$ \\
$18: 1$ n-7 & $3,14 \pm 2,16$ & $0,43 \pm 0,44$ & $0,05 \pm 2,06$ \\
$18: 1$ n-9 & $33,74 \pm 1,67$ & $39,72 \pm 1,10$ & $42,17 \pm 1,84$ \\
$18: 1$ n-11 & $0,26 \pm 0,10$ & $0,03 \pm 1,74$ & $0,06 \pm 1,22$ \\
$18: 2$ n-6 & $13,86 \pm 1,51$ & $19,40 \pm 2,51$ & $7,89 \pm 1,51$ \\
$18: 3$ n-6 & $1,03 \pm 1,24$ & $0,40 \pm 2,16$ & $0,25 \pm 2,10$ \\
$18: 3$ n-3 & $0,68 \pm 0,90$ & $0,67 \pm 0,26$ & $0,33 \pm 1,90$ \\
$20: 1$ n-9 & $1,75 \pm 1,35$ & $1,85 \pm 2,14$ & $0,87 \pm 1,39$ \\
$20: 2$ n-6 & $0,66 \pm 0,51$ & $0,53 \pm 2,19$ & $0,29 \pm 1,04$ \\
$20: 3$ n-9 & $0,27 \pm 1,84$ & $0,50 \pm 1,05$ & $0,25 \pm 2,18$ \\
$20: 4$ n-6 & $1,24 \pm 2,02$ & $1,19 \pm 1,95$ & $0,58 \pm 2,09$ \\
$20: 5$ n-3 & $0,34 \pm 1,44$ & $0,12 \pm 1,55$ & $0,05 \pm 1,66$ \\
$22: 0$ & $0,80 \pm 1,31$ & $0,46 \pm 0,54$ & $0,44 \pm 1,18$ \\
$22: 4$ n-6 & $1,02 \pm 0,48$ & $0,25 \pm 2,09$ & $0,09 \pm 1,76$ \\
$22: 5$ n-3 & $0,36 \pm 0,94$ & $0,06 \pm 1,89$ & $0,04 \pm 2,12$ \\
$22: 5$ n-6 & $0,86 \pm 1,36$ & $0,34 \pm 1,24$ & $0,41 \pm 0,51$ \\
$22: 6$ n-3 & $0,57 \pm 1,84$ & $0,30 \pm 0,86$ & $0,08 \pm 1,43$ \\
\hline
\end{tabular}

Médias \pm desvio padrão. Fonte: Autores (2021).

Quando avaliado o perfil lipídico de farinhas elaboradas a partir de resíduos de processamento de peixes, observa-se que os teores e os tipos de ácidos graxos diferem entre as espécies, principalmente nas espécies de peixes marinhos, em comparação aos de água doce. Souza et al. (2017) avaliaram farinhas elaboradas a partir de resíduos de peixes de água salgada (atum, sardinha e salmão) e de água doce (tilápia) e os teores variaram muito em comparação a este estudo, assim como os tipos de ácidos graxos encontrados em maiores proporções. Estes autores encontraram 29 ácidos graxos, dos quais os de maior representatividade foram o ácido palmítico (16:00), esteárico (18:00), oléico (18:1n-9c), linoléico (18:2n-6) e docosahexaenóico (22:6n-3). As farinhas de sardinha e atum apresentaram predominância do ácido docosahexaenóico (22:6n-3). Para as farinhas de salmão e tilápia, o ácido graxo que apareceu em maior proporção foi o ácido oléico (18:1n-9 c). De acordo com Souza et al. 
(2017), o ácido eicosapentaenóico (EPA, 20:5n-3) e o ácido docosahexaenóico (DHA, 22:6n-3) foram encontrados em menores proporções na farinha de tilápia em comparação às demais farinhas analisadas, com valores de $0,15 \mathrm{~g} / \mathrm{kg}$ e $3,2 \mathrm{~g} / \mathrm{kg}$, respectivamente. O perfil de ácidos graxos da farinha de tilápia desenvolvida por Souza et al. (2017) foi similar ao encontrado no presente estudo.

No presente estudo, os ácidos graxos de grande importância fisiológica e nutricional, alfa-linolênico (LNA, 18:3n-3); eicosapentaenóico (EPA, 20:5n-3) e docosahexaenóico (DHA, 22:6n-3) foram encontrados nas farinhas, com valores médios de $0,57 \% ; 0,17 \%$ e $0,32 \%$ respectivamente. Pode-se observar que a farinha obtida a partir das carcaças de tilápia apresentou maiores quantidades desses ácidos graxos $(0,68 \% ; 0,34 \%$ e $0,57 \%$, respectivamente), quando comparada às demais farinhas (Tabela 5).

Tabela 5. Somatório e relação de ácidos graxos (\%) nas farinhas elaboradas com diferentes espécies de peixes.

\begin{tabular}{lccccccc}
\hline \multicolumn{1}{c}{ Farinhas } & AGPI & AGMI & AGS & n-6 & n-3 & AGPI/AGS & n-6/n-3 \\
\hline Tilápia & 20,90 & 45,26 & 33,84 & 18,67 & 1,96 & 0,62 & 10,94 \\
Carpa & 23,80 & 47,03 & 29,16 & 22,13 & 1,17 & 0,82 & 19,70 \\
Pacu & 10,03 & 50,38 & 39,59 & 9,27 & 0,51 & 0,25 & 19,62 \\
\hline
\end{tabular}

AGPI (somatório dos ácidos graxos poliinsaturados); AGMI (somatório dos ácidos graxos monoinsaturados); AGS (somatório dos ácidos graxos saturados); n-6 (somatório dos ácidos graxos da série n-6); n-3 (somatório dos ácidos graxos da série n-3); AGPI/AGS (relação entre o somatório dos ácidos graxos poliinsaturados e saturados); n-6/n-3 (relação entre o somatório dos ácidos graxos da série n-6 e n-3). Fonte: Autores (2021).

Na Tabela 5 observa-se que os valores de ácidos graxos poli-insaturados (AGPI) foram superiores para a farinha obtida a partir das carcaças de carpa. Para a relação AGPI/AGS, os valores variaram de 0,25 a 0,82. Em geral, uma proporção de AGPI/AGS maior que 0,45 é recomendada em dietas humanas para prevenir o desenvolvimento de doenças cardiovasculares e algumas doenças crônicas como o câncer (Wołoszyn et al., 2020).

Quanto à questão nutricional, não há um consenso entre os pesquisadores nos valores ideais da razão n-6/n-3 indicados à dieta. Conforme Wołoszyn et al. (2020), a razão n-6 / n-3 inferior a 4,0 indica quantidades desejáveis de ácidos graxos n-3 e n-6, enquanto Simopoulos (1999) recomenda valores entre 5 e 10. Nos países ocidentais modernos, a proporção da ingestão de n-6 / n-3 na dieta é de até 20-30: 1 (Chilton et al., 2017), uma razão extremamente alta, pois a ideal seria de 1 a 2:1, de acordo com Schmidt (2000) e Simopoulos et al. (1999).

Os valores encontrados para a relação n-6/n-3 nas farinhas variaram de 10,94 a 19,70, sendo a menor relação, atribuída à farinha de carcaça de tilápia. Segundo Steffens (1997), os valores desta razão em peixes de água doce não cultivados (habitat natural) variam entre 0,25 e 1 , sendo esta razão menor em peixes marinhos.

Os peixes de ambientes naturais consomem maior quantidade de n-3 devido ao fato de sua dieta conter níveis mais elevados destes ácidos graxos (Hossain, 2011), diferente dos peixes de cultivo, cujas rações tem buscado a substituição do óleo de peixe (rico em AGPI da série n-3) por óleos vegetais, que possuem baixos teores de AGPI de cadeia longa da série n-3 (Turchini et al., 2009). Desta forma, o resultado do presente experimento, com relação à razão n-6/n-3, mostra que possivelmente a composição da ração fornecida aos peixes pode ter influenciado a razão n-6/n-3, ou seja, elevando as quantidades de ácidos graxos n-6 em relação aos n-3. Além disso, é importante conhecer as quantidades de fitoplâncton e zooplâncton presentes na água e o tipo de alimentação do peixe, pois a quantidade de ácidos graxos poli-insaturados presentes na carne dos peixes varia principalmente em função do tipo de alimentação, além de outros fatores, como temperatura, salinidade, estação, tamanho, idade, habitat da espécie e estágio de vida (Hossain, 2011). 


\section{Teor de minerais}

Não houve diferença estatítica na composição mineral (cálcio, ferro e fósforo) das farinhas elaboradas, com as diferentes espécies de peixes (Tabela 6).

Tabela 6. Composição mineral (mg/100g) das farinhas elaboradas com diferentes espécies de peixes.

\begin{tabular}{cccc}
\hline Farinha & Cálcio & Ferro & Fósforo \\
\hline Tilápia & $1,68 \pm 0,10$ & $2,63 \pm 0,25$ & $5,76 \pm 0,24$ \\
Carpa & $1,74 \pm 0,22$ & $1,67 \pm 0,45$ & $4,23 \pm 0,11$ \\
Pacu & $1,92 \pm 0,39$ & $2,78 \pm 0,82$ & $5,96 \pm 0,36$ \\
\hline Teste F & $1,12 \mathrm{~ns}$ & $2,31 \mathrm{~ns}$ & $1,78 \mathrm{~ns}$ \\
C.V $(\%)$ & 17,26 & 46,82 & 17,91 \\
\hline
\end{tabular}

Médias \pm desvio padrão. ns - não significativo, indica que não há diferença estatística significativa entre as amostras. Fonte: Autores (2021).

Dentre os minerais analisados, o fósforo se mostrou o mais abundante nas farinhas elaboradas, apresentando teor médio de 5,38 mg/100g. Para crianças de 1 a 4 anos, a ingestão média recomendada de fósforo é de $380 \mathrm{mg} / \mathrm{dia}$ (Butte et al., 2010). O fósforo é um nutriente essencial, componente das membranas celulares e participante de ciclos de energia celular, moléculas e enzimas que codificam e regulam todas as informações genéticas e sintéticas, bem como uma infinidade de outras vias metabólicas críticas a todas as formas de vida (Uribarri \& Calvo, 2018).

As farinhas apresentaram teor médio de ferro de $1,96 \mathrm{mg} / 100 \mathrm{~g}$. Esse valor pode ser considerado representativo quando comparado a outros alimentos como fígado bovino cru (12,10 mg/100g); farinha de soja $(9,10 \mathrm{mg} / 100 \mathrm{~g})$; beterraba crua $(2,50$ $\mathrm{mg} / 100 \mathrm{~g}$ ); banana da terra (1,40 mg/100g) e espinafre cru (3,08 mg/100g) (Godoy et al., 2013). Recomenda-se a ingestão de 3 $\mathrm{mg} /$ dia de ferro para crianças de 1 a 4 anos (Butte et al., 2010). Estima-se que em torno de 1,24 bilhão de indivíduos sofram de anemia por deficiência de ferro, embora com grandes variações de países de baixa a alta renda (Kassebaum et al., 2014). O ferro tem papel fisiológico essencial, pois está envolvido no transporte de oxigênio e na formação de energia (Moustarah \& Mohiuddin, 2019).

O cálcio apresentou valor médio de $1,77 \mathrm{mg} / 100 \mathrm{~g}$ nas farinhas elaboradas. Recomenda-se a ingestão de $500 \mathrm{mg} / \mathrm{dia}$ de cálcio para crianças de 1 a 4 anos (Butte et al., 2010). Além de sua função na construção de ossos e dentes, o cálcio é essencial na contração muscular, ativação do oócito, coagulação do sangue, impulsos nervosos, transmissão, regulação do batimento cardíaco e equilíbrio de fluidos dentro das células (Pravina et al., 2013). A deficiência de cálcio a longo prazo pode levar à oestoporose, na qual o osso se deteriora e há um aumento do número de fraturas (Pravina et al., 2013).

Souza et al. (2017) relataram uma grande variação nos teores de minerais em farinhas elaboradas com resíduos de processamento de diferentes espécies de peixes (atum, sardinha, salmão e tilápia), cujos valores foram de 0,9\% a 9,37\% para cálcio, $0,91 \%$ a $6,08 \%$ para fósforo, e de $35,18 \mathrm{mg} / \mathrm{kg}$ a $121,95 \mathrm{mg} / \mathrm{kg}$ para o ferro, sendo que a farinha de tilápia apresentou 9,37\% de cálcio, 6,08\% de fósforo e 3,518 g/100 g de ferro. Justen et al. (2017) que aplicaram metodologia muito semelhante a utilizada neste experimento, obtiveram farinhas de tilápia contendo 6,57 g/100g de cálcio, 3,52 g/100g de fósforo e 6,36 g/100g de ferro.

A variação que ocorre nos teores de minerais depende da espécie de peixe e do tipo de resíduo utilizado para a elaboração da farinha, incluindo a presença ou não de estrutura óssea. Quanto menor a quantidade de espinhaço ou costelinhas, menor será a quantidade de cálcio presente na farinha, uma vez que os ossos de peixes possuem alto conteúdo de minerais, sendo inclusive adequados como fonte natural de cálcio (Malde et al., 2010). 


\section{Análises microbiológicas}

Na Tabela 7 estão dispostos os resultados das análises microbiológicas das carcaças in natura e das farinhas elaboradas.

Tabela 7. Resultados das análises microbiológicas das carcaças in natura e das farinhas preparadas com diferentes espécies de peixes.

\begin{tabular}{|c|c|c|c|c|c|c|}
\hline & \multicolumn{3}{|c|}{ Carcaça in natura } & \multicolumn{3}{|c|}{ Farinhas } \\
\hline & Tilápia & Carpa & Pacu & Tilápia & Carpa & Pacu \\
\hline Coliformes a $35^{\circ} \mathrm{C}(\mathrm{NMP} / \mathrm{g})$ & 23 & 11 & $<11$ & 11 & $<11$ & $<11$ \\
\hline Coliformes a $45^{\circ} \mathrm{C}(\mathrm{NMP} / \mathrm{g})$ & 23 & 11 & $<11$ & 11 & $<11$ & $<11$ \\
\hline Estafilococos coagulase positiva (UFC/g) & 40 & 10 & 10 & $<20$ & $<10$ & $<10$ \\
\hline Salmonella $\mathrm{ssp} / 25 \mathrm{~g}$ & ausente & ausente & ausente & ausente & ausente & ausente \\
\hline
\end{tabular}

NMP: Número mais provável; UFC: Unidade Formadora de Colônia. Fonte: Autores (2021).

Trabalhos anteriores relatam que valores menores de $10^{2} \mathrm{NMP} / \mathrm{g}$ para coliformes a 35 e $45^{\circ} \mathrm{C}$, menores que $10^{2} \mathrm{UFC} / \mathrm{g}$ de Estafilococos coagulase positiva e ausência de Salmonella ssp em 25 gramas de amostra indicam que produtos com inclusão de farinha de peixe possuem padrão microbiológico aceitável para o consumo humano (Goes et al., 2016a; Kimura et al., 2017; Souza et al., 2021). Comparando o número de coliformes e estafilococos coagulase positiva entre as carcaças in natura das três espécies de peixes, pode-se verificar que elas já estavam dentro destes limites antes do processo de defumação. Com o processo de defumação, a temperatura aplicada e o tempo de exposição das carcaças aos compostos da fumaça, promoveram a redução do número de microrganismos, o que fica evidenciado na qualidade das farinhas (Tabela 7). Segundo Girard (1991) a temperatura da defumação é muito importante na redução dos microrganismos, juntamente com a ação dos compostos bactericidas presentes na fumaça.

O processo de defumação confere ao alimento barreiras físicas e químicas eficientes contra a penetração e atividade de microrganismos, decorrente da perda da água e à ação dos próprios constituintes da fumaça (Maga, 1988). Os resultados mostram que a higiene-sanitária adotada na elaboração das farinhas foi adequada, sendo, portanto, viável para consumo humano. Todavia, os altos teores de umidade das farinhas são preocupantes, em função da redução do tempo de vida útil, devido ao maior risco de desenvolvimento de microrganismos.

Vários trabalhos têm relatado boa qualidade microbiológica de farinhas elaboradas a partir de resíduos de filetagem de peixes, que normalmente são desprezados na unidade de beneficiamento (Godoy et al., 2013; Goes et al., 2016b; Souza et al., 2021). Esses resíduos, quando bem manipulados, quanto à higiene-sanitária, e mantidos em temperatura controlada adequada dentro da indústria de processamento, proporcionam um produto final com excelente qualidade microbiológica, desde que também seja aplicada uma boa metodologia de elaboração da farinha, evitando-se uma possível contaminação na etapa de produção da farinha, por parte dos funcionários, ou até mesmo por equipamentos e utensílios contaminados.

\section{Conclusão}

As farinhas elaboradas a partir das carcaças das três espécies de peixe apresentaram-se como um produto com elevado teor de proteína bruta, minerais (cálcio, ferro e fósforo) e lipídios totais e apresentaram ácidos graxos essenciais, que são de grande importância para a nutrição humana, como os ácidos linoléico, alfa-linolênico, eicosapentaenóico (EPA) e docosahexaenóico (DHA). Os resultados microbiológicos das farinhas obedeceram aos limites estabelecidos pela legislação 
brasileira, portanto, podem ser utilizadas no enriquecimento e elaboração de diversos produtos para o consumo humano. Além de apresentar potencial econômico para cadeia produtiva em questão, a produção de farinha de peixes contribui com a sustentabilidade e paralelamente, amenizar o impacto que os resíduos causariam ao meio ambiente.

Para futuros trabalhos, sugere-se o estudo do aprimoramento do processo de desidratação das farinhas, objetivando diminuir o teor de umidade final e promover uma concentração maior dos nutrientes. O desenvolvimento de produtos com a incorporação das farinhas de peixe também pode trazer alternativas para a sua disseminação, e possível produção industrial.

\section{Referências}

American Public Health Association -APHA. (2001). Compendium of methods for the microbiological examination of foods. APHA

AOAC. Association of Official Analytical Chemists. (2010). Official methods of analysis of the AOAC International. 18th Ed., 3th Rev: Washington, DC.

Bligh, E. G \& Dyer, W. J. (1959). A rapid method of total lipid extraction and purification. Canadian Journal of Biochemistry and Physiology, $37(8), 911-17$.

Brasil. (1997). Ministério da Agricultura e do Abastecimento. Secretaria de Defesa Agropecuária - DAS. Departamento de Inspeção de Produtos de Origem Animal DIPOA. Divisão de Normas Técnicas - DNT. Decreto Lei no 30.691, de 29 de março de 1952, alterado pelos Decretos nº 1.255 , de 25 de junho de 1962, $\mathrm{n}^{\circ} 1.236$, de 2 de setembro de 1994, $\mathrm{n}^{\circ} 1.812$, de 18 de fevereiro de 1996, e $\mathrm{n}^{\circ} 2.244$ de 4 de junho de 1997. Regulamento da Inspeção Industrial e Sanitária de Produtos de Origem Animal. Brasília, DF, 1997. 241 p.

Butte, N. F., Fox, M. K., Briefel, R. R., Siega-Riz, A. M., Dwyer, J. T., Deming, D. M., \& Reidy, K. C. (2010). Nutrient intakes of US infants, toddlers, and preschoolers meet or exceed dietary reference intakes. Journal of the American Dietetic Association, 110(12), S27-S37.

Chilton, F. H., Dutta, R., Reynolds, L. M., Sergeant, S., Mathias, R. A., \& Seeds, M. C. (2017). Precision nutrition and omega-3 polyunsaturated fatty acids: A case for personalized supplementation approaches for the prevention and management of human diseases. Nutrients, 9(11), 1165.

Clement, S., \& Lovell, R. T. (1994). Comparison of processing yield and nutrient composition of cultured Nile tilapia (Oreochromis niloticus) and channel catfish (Ictalurus punctatus). Aquaculture, 119(2-3), 299-310.

Eijsink, L. M., Krom, M. D., \& De Lange, G. J. (1997). The use of sequential extraction techniques for sedimentary phosphorus in eastern Mediterranean sediments. Marine Geology, 139(1-4), 147-155.

Gil, A., \& Gil, F. (2015). Peixe, uma fonte mediterrânea de PUFA n-3: Os benefícios não justificam a limitação do consumo. British Journal of Nutrition, 113 (S2), S58-S67.

Girard, J. P. (1991). Tecnología de la carne y de los productos cárnicos (No. 637.5 G4412t Ej. 1 018942). Acribia.

Godoy, L. C., Franco, M. L. R. S., Souza, N. E., Stevanato, F, B. \& Visentainer, J. V. (2013). Development, preservation, and chemical and fatty acid profiles of nile tilpaia carcass meal for humanfeeding. Journal of Food Processing and Preservation, 37(2), 93-99.

Goes, E. S.R., Souza, M. L. R., Kimura, K. S., Coradini, M. F., Verdi, R., \& Mikcha, J. M. G. (2016a). Inclusion of dehydrated mixture made of salmon and tilapia carcass in spinach cakes. Acta Scientiarum. Technology, 38(2), 241-246.

Goes, E. S. R., Souza, M. L. R., Michka, J. M. G., Kimura, K. S., Lara, J. A. F., Delbem, A. C. B., \& Gasparino, E. (2016b). Fresh pasta enrichment with protein concentrate of tilapia: nutritional and sensory characteristics. Food Science and Technology, 36(1), 76-82.

Gonçalves, A. A., \& Prentice-Hernández, C. (1998). Fumaça líquida: uma tecnologia para defumar pescado. Boletim SBCTA, 32(2), 189-199.

Hossain, M. A. (2011). Fish as source of n-3 polyunsaturated fatty acids (PUFAs), which one is better-farmed or wild. Advance Journal of food science and technology, 3(6), 455-466.

IBGE - Instituto Brasileiro de Geografia e Estatística. (2020). Produção da Pecuária Municipal 2019. https://biblioteca.ibge.gov.br/visualizacao/periodicos/84/ppm_2019_v47_br_informativo.pdf

Idea, P., Pinto, J., Ferreira, R., Figueiredo, L., Spínola, V., \& Castilho, P. C. (2020). Fish processing industry residues: A review of valuable products extraction and characterization methods. Waste and Biomass Valorization, 11(7), 3223-3246.

Ikape, S. I., \& Solomon, S. G. (2018). Filleting yield, body characteristics and length weight relationship of four fish species from lower River Benue Makurdi Nigeria. Aquatic Research, 1(3), 115-126.

International Organization For Standardization (ISO 5509). 1978. Animal and vegetable fats and oils - Preparation of methyl esters of fatty acids.- ISO, 1-6.

Justen, A. P., Souza, M. L. R., Monteiro, A. R., Mikcha, J. M., Gasparino, E., Delbem, Á. B., Carvalho, M. R. B., Del Vesco, A. P. (2017). Preparation of extruded snacks with flavored flour obtained from the carcasses of Nile tilapia: physicochemical, sensory, and microbiological analysis. Journal of Aquatic Food Product Technology, 26(3), 258-266.

Kassebaum, N. J., Jasrasaria, R., Naghavi, M., Wulf, S. K., Johns, N., Lozano, R., ... \& Murray, C. J. (2014). A systematic analysis of global anemia burden from 1990 to 2010. Blood, The Journal of the American Society of Hematology, 123(5), 615-624. 
Kimura, K. S., Souza, M. L. R., Gasparino, E., Mikcha, J. M. G., Chambó, A. P. S., Verdi, R., ... \& Goes, E. S. R. (2017). Preparation of lasagnas with dried mix of tuna and tilapia. Food Science and Technology, 37, 507-514.

Maga, J. (1988). A smoke in food processing. Colorado, Florida: CRC Press.

Malde, M. K., Graff, I. E., Siljander-Rasi, H., Venäläinen, E., Julshamn, K., Pedersen, J. I., \& Valaja, J. (2010). Fish bones-a highly available calcium source for growing pigs. Journal of animal physiology and animal nutrition, 94(5), e66-e76.

Marti-Quijal, F. J., Remize, F., Meca, G., Ferrer, E., Ruiz, M. J., \& Barba, F. J. (2020). Fermentation in fish and by-products processing: An overview of current research and future prospects. Current Opinion in Food Science, 31, 9-16.

Moustarah, F., \& Mohiuddin, S. S. (2019). Dietary iron. Treasure Island (FL): StatPearls Publishing.

Pateiro, M., Munekata, P. E., Domínguez, R., Wang, M., Barba, F. J., Bermúdez, R., \& Lorenzo, J. M. (2020). Nutritional profiling and the value of processing by-products from gilthead sea bream (Sparus aurata). Marine drugs, $18(2), 101$.

Peixe BR. (2021). Associação Brasileira de Piscicultura. Anuário Peixe BR da Piscicultura 2021. São Paulo: Peixe BR.

Pinheiro, L. M. S., Martins, R. T., Pinheiro, L. A. S., \& Pinheiro, L. E. L. (2006). Rendimento industrial de filetagem da tilápia tailandesa (Oreochromis spp.). Arquivo Brasileiro de Medicina Veterinária e Zootecnia, 58, 257-262.

Rodríguez, R., Fountoulaki, E., Grigorakis, K., Alexis, M., \& Flos, R. (2010). Season and size effects: changes in the quality of gilthead sea bream (Sparus aurata L.). Mediterranean Marine Science, 11(1), 117-132.

Rørå, A. M. B., Kvåle, A., Mørkøre, T., Rørvik, K. A., Hallbjoørn, S., Thomassen, S., \& Magny, S. (1998). Process yield, colour and sensory quality of smoked Atlantic salmon (Salmo salar) in relation to raw material characteristics. Food Research International, 31(8), 601-609.

Schmidt, M. A. (2000). Gorduras inteligentes. São Paulo: Editora Roca LTDA.

Sigurgisladottir, S., Sigurdardottir, M. S., Torrissen, O., Vallet, J. L., \& Hafsteinsson, H. (2000). Effects of different salting and smoking processes on the microstructure, the texture and yield of Atlantic salmon (Salmo salar) fillets. Food Research International, 33(10), 847-855.

Silva, A. (2000). Composição lipídica e quantificação dos ácidos graxos polinsaturados EPA (20: 5 n-3) e DHA (22: 6 n-3) de peixes de água doce. (2000). Tese (Doutorado em Ciência de Alimentos). Faculdade de Engenharia de Alimentos, Universidade Estadual de Campinas, Campinas.

Silva, D. J. \& Queiroz, A. C. (2002). Análise De Alimentos: Métodos Químicos e Biológicos. (3a ed.), Universidade Federal de Viçosa, p. $235,2002$.

Simopoulos, A. P., Leaf, A., \& Salem, N. (1999). Essentiality of and recommended dietary intakes for omega-6 and omega-3 fatty acids. Annals of nutrition \& metabolism, 43(2), 127-130

Souza, M. L. R. (2002). Comparação de seis métodos de filetagem, em relação ao rendimento de filé e de subprodutos do processamento da Tilápia-do-Nilo (Oreochromis niloticus). Revista Brasileira de Zootecnia, 31, 1076-1084.

Souza, M. L. R. (2003). Processamento do filé e da pele da tilápia do Nilo (Oreochromis niloticus): Aspectos tecnológicos, composição centesimal, rendimento, vida útil do filé defumado e teste de resistência da pele curtida (Tese de Doutorado em Aquicultura). Centro de Aquicultura da Universidade Estadual Paulista (UNESP/Jaboticabal), Jaboticabal.

Souza, M. L. R., Yoshida, G. M., Campelo, D. A. V., Moura, L. B., Xavier, T. O., \& dos Reis Goes, E. S. (2017). Formulation of fish waste meal for human nutrition. Acta Scientiarum. Technology, 39, 525-531.

Souza, M. L. R., Viegas, E. M. M., Kronka, S. N., Amaral, L. A., Parisi, G., Coradini, M. F., \& Goes, E. S. R. (2020). Cold and hot smoked nile tilapia fillets: quality and yield of pigmented and unpigmented fillets. Italian Journal of Food Science, 32(2), 450-465.

Souza, M. L. R., Urbich, A. V., Müller, B.O., Coradini, M. F., Oliveira, G. G., Matiucci, M. A., ... \& Goes, E. S.R. (2021). Sopa instantânea com inclusão de farinhas de peixes. Research, Society and Development, 10(8), e35910817247-e35910817247.

Steffens, W. (1997). Effects of variation in essential fatty acids in fish feeds on nutritive value of freshwater fish for humans. Aquaculture, 151(1-4), 97-119.

Strànsky, K., Jursík, T., \& Vítek, A. (1997). Standard equivalent chain length values of monoenic and polyenic (methylene interrupted) fatty acids. Journal of High Resolution Chromatography, 20(3), 143-158.

Turchini, G.M.; Torstensen, B.E.; Ng, W.K. (2009). Fish oil replacement in finfish nutrition. Reviews in Aquaculture, 1(1), 10-57.

Uribarri, J., \& Calvo, M. S. (2017). Dietary Phosphorus: Health, Nutrition, and Regulatory Aspects. Boca Raton: CRC Press, Taylor \& Francis Group.

Visentainer, J. V. (2003). Composição de ácidos graxos e quantificação dos ácidos graxos LNA, EPA e DHA no tecido muscular de tilápias (Oreochromis niloticus), submetidas a diferentes tratamentos com óleo de linhaça. Tese. Campinas: Universidade Estadual de Campinas.

Wołoszyn, J., Haraf, G., Okruszek, A., Wereńska, M., Goluch, Z., \& Teleszko, M. (2020). Fatty acid profiles and health lipid indices in the breast muscles of local Polish goose varieties. Poultry science, $99(2), 1216-1224$.

Zara, R. F. (2005). Qualidade de filés de Tilápia do Nilo (Oreochromis niloticus) submetidos à defumação com extrato aquoso de alecrim (Rosmarinus officinalis). Dissertação (Mestrado em Química). Universidade Estadual de Maringá.

Zhou, H. Y., Cheung, R. Y. H., Chan, K. M., \& Wong, M. H. (1998). Metal concentrations in sediments and tilapia collected from inland waters of Hong Kong. Water Research, 32(11), 3331-3340. 